\title{
Development of a feature -based Computer-Aided Fixturing system
}

G. M. Pereira

UNISINOS - Av. UNISINOS 950 - 93022-000 - S. Leopoldo, RS

E-mail: gian@indus.unisinos.tche.br

G. D. Cunha

PUCRS - Av. Ipiranga 6681-90619-900 - P. Alegre, RS Brazil /E-mail: gcunha@vortex.ufrgs.br

\begin{abstract}
This paper introduces the specification requirements of a Computer-Aided Fixturing (CAF). It is based on the feature-based approach. The system is supposed to perform the selection and positioning of fixturing modular elements for machining operations.
\end{abstract}

Keywords

Fixturing / CAF / CAPP / CAD / CIM / Features Technology

\section{INTRODUCTION.}

The workpiece fixturing design is a key element to achieve machine set-up time reduction. It is especially critical for the milling process. The effective set-up makes the use of automated machining equipment more efficient and profitable. Nevertheless the design or the selection of the fixturing may be a very complex issue - frequently more difficult to be performed than the product design itself. By 
having not reached a good fixturing solution for a specific manufacturing operation the set-up times may rise quite significantly. This is why much effort has been done in order to reduce the fixturing creation task.

Some relevant support has been offered to fixturing designers by introducing the possibility of using kits of modular fixtures which can be assembled to compose the fixturing.

Another very important support is given by the use of the Computer-Aided Fixturing (CAF) systems, which may reduce considerably the need for testing some new CNC programs. These systems are usually conceived to evaluate the fixturing reliability.

Notice that in the lack of such an analysis many process engineers choose to adopt suboptimal machine working parameters thus leading to longer processing times. Moreover, there is also a need for checking the workpiece integrity. Normally the analysis on the occurrence of part geometric deformations and dimensional inaccuracies produced by the fixturing is missed during the product design or product process planning stages.

This work presents a model for a CAF system which was conceived to allow fixturing designers to select modular fixtures for the milling process which can efficiently interact with CAPP systems. It may be pointed out the availability of such a system should greatly contribute to the reduction in set-up times of automated milling equipment thus enabling the achievement of higher productivity levels by allowing the selection of optimised operational parameters.

\section{THE FEATURE-BASED CAF SYSTEM.}

The design of the proposed system concerning this approach is based on the feature-based technology as indicated by Shah (1991). Particularly the information about part geometry is key to the development of the CAF system - Liou \& Suen (1991). This system was conceived to operate coupled with a feature-based CAD system developed upon the design by features and parametric design concepts. The design by features approach is based on the synthesis of volumetric elements as described by Cunha \& Teixeira (1993) and Cunha (1995).

In the particular case of the geometric part modeller being used individual mechanical components are built as a set of aggregate form features, which are volume units that possess dimensional and topological properties. In this model it is possible to identify univocal surfaces, lines, edges and points in the form features. 
The form features themselves are of two main types: primitive geometric entities (solids described by the Spatial Geometry) and specific engineering design entities ( holes, slots, keyways, pockets, etc.). The selection and classification of the features to be handled by computer systems depend on the specific systems application domains. In the scope of devising an assistance system for fixturing design, the analysis was focused on the elicitation of features functionally and geometrically related to the fixtures.

\section{BASIC REQUIREMENTS OF CAF SYSTEMS.}

Ferreira \& Liu (1988) propose the structuring of a system used to design fixturing based on kits of modular tools for machine milling operations will become an essential element in the integration of the different systems used in computerintegrated manufacturing systems, such as CAD, CAPP and CAM.

The following observations should be made in this concept:

$\checkmark \quad$ the design of the mechanical parts is directly affected by the feasibility of their manufacturing process;

$\checkmark$ the process planning should take into account the feasibility of the manufacturing operations in terms of geometric interferences between cutting tools and fixtures;

$\checkmark \quad$ the tool path creation by the CAM system should take into consideration these geometric interferences.

As a consequence, we can say the activities of part design, process planning and manufacturing will be undoubtedly affected by the workpiece fixturing. Therefore, the issues related to the selection of a given fixturing should be considered when establishing the information flow for the computer systems used to support these activities (CAD, CAPP, CAM).

Ferreira \& Liu (1988), Pham \& Lazaro (1989) and Cabadaj (1990) proposed all information concerning the type of machine, the tools adopted, the operations selected, their stages of development in terms of dimensional and geometric precision and the surface finishing should be readily available in a database to be used by the CAF system, thus allowing it to select the workpiece milling areas, the fixturing areas and the cutting tool access areas.

As far as the integration of the CAD/CAPP/CAF/CAM systems is concerned, it turns necessary to use a graphic engine of some CAD system. In this approach, the CAF system is implemented as a specialized module which acts over the CAD system while making use of the graphic environment available.

In addition to the graphic system, the access to a structured database is needed in order to hold the relevant information about the kits of modular fixtures available 
in the market and to store the solutions selected by the CAF system. The use of knowledge engineering techniques has been adopted for the fixture selection as well as for the fixtures positioning around the workpiece as shown by Caillaud \& Noyes (1996).

The CAF systems must also deal with another very important issue: the selection of workpiece and fixtures spatial orientation. Ferreira \& Liu (1988) introduced an approach based on the use of knowledge rules to eliminate several of the possible workpiece positions. This was made possible by first establishing a condition by which each possible workpiece position is subject to the existence of at least one machining axis associated with some existing workpiece form feature. Then the designer was supposed to select, according to the production conditions, the different acceptable workpiece positions corresponding to the process fixturing requirements.

Pham \& Lazaro (1989) proposed the use of knowledge rules to identify the workpiece form features which could be used for the fixtures positioning. This analysis was based on the use of modular fixtures.

\section{FIXTURING STRESS EVALUATION.}

It must be reminded the mere selection and positioning of a set of fixtures cannot guarantee the workpiece will not be affected by the stresses generated by the machining operations. Eventually it turns necessary to evaluate the workpiece deformation which can be accomplished by applying numerical analysis - provided by different methods as the Finite Elements Method for instance. But it must be taken into account this may be a quite time-consuming task.

The workpiece deformation must be avoided either because of affecting part integrity or generating part dimensional and geometric inaccuracy. In any case fixturing configuration must be changed - maybe by moving, adding or deleting fixtures. Notice this new fixturing solution will require another analysis on the workpiece rigidity.

\section{STRUCTURING THE CAF SYSTEM.}

The proposed approach is based on identifying workpiece form features (and their related geometric elements, as surfaces) which match the fixtures form features. It supposes the workpieces, final parts and fixtures are modelled using the same geometric modeller. The fixturing elements are mechanical components therefore, their representation will also be performed by using the feature-based part description model. 
The part description provided by the feature-based geometric model was enhanced in order to provide the information to enable the fixturing analysis. This required the set of form features and the structure of the form features data description to be revised. Notice the same part description model was previously used as a basis for devising an expert system for both the design for manufacture and assembly analysis and the process selection analysis as presented by Cunha \& Teixeira (1993) and Cunha (1995).

The use of such a structure for information representation allows the system database to be accessed by knowledge rules. It may lead to the adequate composition of the fixturing for a particular manufacturing operation, including fixture selection (clamps, bedding supports, down-hold clamps, etc.) and locating elements selection (locating pins, center bolts, cylindrical stops, etc.).

\section{SELECTION OF FIXTURING FEATURES.}

Next it will be presented the structured set of information conceived to enable the introduction of the 'fixturing features' in the part representation model - Pereira (1996). Notice it is necessary to describe either the workpiece or the fixtures in terms of fixturing features (along with other classes of features as geometric, precision, material features, etc.). These features will also be used by the CAF system for identification purposes. The information described was added to the original feature-based part representation model described by Cunha (1995).

For the workpiece group, the following subset of features were created:

$\checkmark \quad$ specification on fixturing class (there are two types of geometric entities upon which the modular fixtures will operate on fixturing: diameters or surfaces);

$\checkmark \quad$ attributes of this class (internal or external for the diameters; notched, planar or curved for the surfaces);

$\checkmark \quad$ form feature dimensions and inter-form features dimensions inherent to the fixture specification;

$\checkmark \quad$ form features locating references (which consist of a grid of potential points which can be used to place the fixture elements);

$\checkmark \quad$ preferable points for fixture location (which from this point and on will be designated 'hot points' - as seen in figure 1);

$\checkmark \quad$ process references (part-shape details specifically created to ease or allow performing some manufacturing operation);

$\checkmark$ identification on form features (which will be associated to the correspondent fixture form features);

identification on form feature-geometric entities (which will be associated to correspondent form features-geometric entities from the fixture elements). 
For the fixtures, the subset of fixturing features consist of the following:

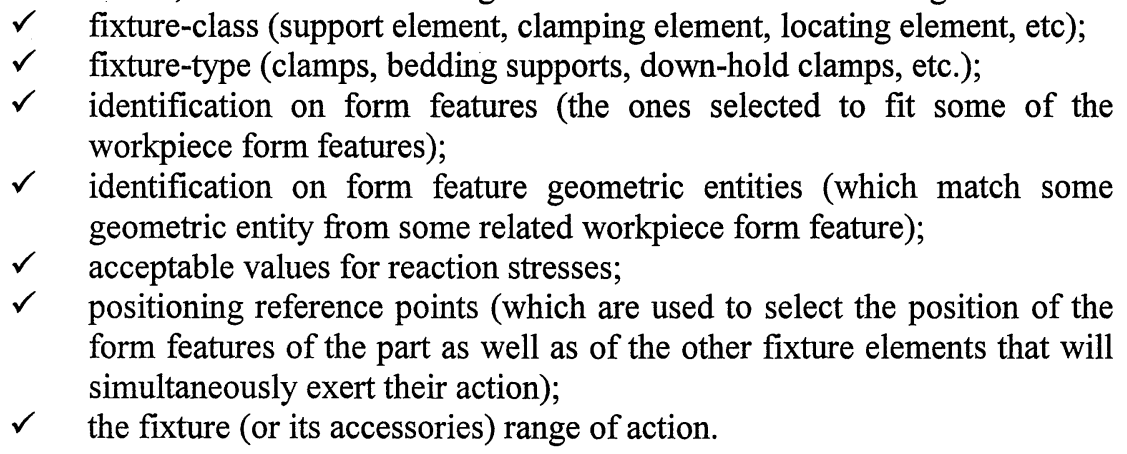

Hot Point - Helps the fixturing process

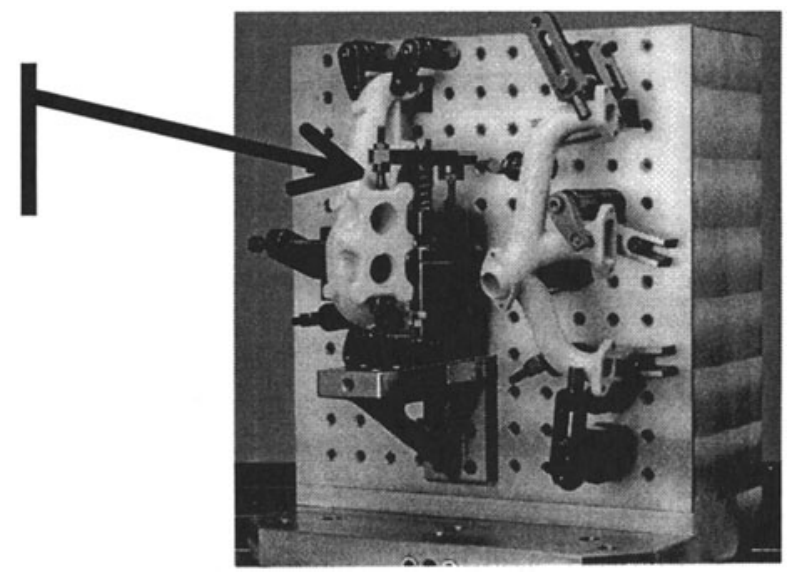

Figure 1 - Hot point in a complex part.

Once the workpiece features and the fixturing features have been defined, the CAF system will proceed to define each fixture to be allocated to the workpiece holding (upon checking the knowledge rules).

The selection of the workpiece form features can be effectively made by searching for the hot points and for the previously mentioned process references which can be found in the part geometric model. In addition, the geometric model itself can be used to enable the identification of the possible fixtures positioning and fastening points.

Since the correspondent points between the workpiece and the fixtures have been defined, the CAF system will be able to start selecting the most suitable modular elements for the set of manufacturing operations previously defined by the CAPP see figure 2. It must be reminded that locating references can be used to limit the number of possible alternatives for part fixturing. 
This will mainly be performed by first matching the geometric entities types from the workpiece form features to the related geometric entities types from the fixture form features and then checking the fixtures capabilities and the manufacturing operation feasibility (considering the use of some specific fixtures). This will guarantee the fixturing process plan requirements are accomplished. Once the CAF system detects a problem with a given operation, it is reported to the user (the process engineer). Notice the CAF system will take into consideration the distribution and the magnitude of the machining stresses before selecting the appropriate fixture elements.

At this point the detailing level of process plan operations should be rather superficial because complete specifications should only be produced after the fixturing has been defined. It should consist of the minimal necessary information to enable the comprehension on the operations performing (including the workpiece fixturing). This can be ensured by running an analysis of the process selection which will presumably have been executed by the CAPP system. Cunha (1995) introduced a study on the problem of manufacturing process selection based on the information provided by the designer through a CAD system.

Connection between the part feature and the fixture feature

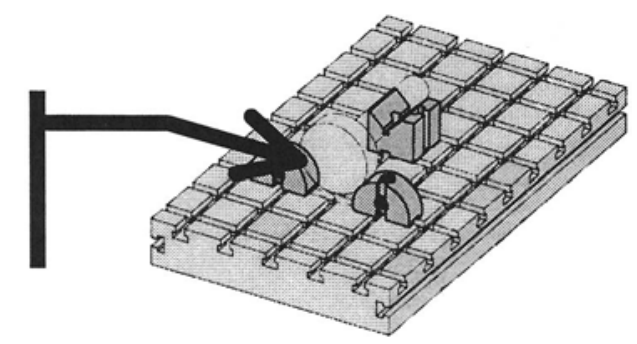

Figure 2 - A simple example of features matching.

\section{THE CAF SYSTEM PROCEDURE.}

The CAF system must select the different workpiece positions required by the machining operations. This will be done by checking the geometric part models provided by the CAD system. Specifically for this operation, the CAF system will analyse all the workpiece fixturing features and it will find the available form features for fixturing. In addition, the system will access the fixtures database in order to operate on the fixture geometric models. It will also access files containing the process plan description as generated by the CAPP system.

Based on all information described above and guided by the set of knowledge rules, the CAF system will proceed to recognise the fixturing positions. In order to do it, the CAF system will group all process requirements specified by the CAPP 
systems in three groups of reference planes. These planes are $\mathrm{XY}, \mathrm{XZ}$ and $\mathrm{YZ}$, as usually adopted in the machining centres.

Notice the process of grouping operations in the reference planes can generate more than one solution for a given set of process requirements specified by the CAPP system. In fact, each different possibility of grouping operations in the reference planes could be referred to as an available fixturing position.

Once identified a possibility of grouping the operations in the reference planes the CAF system will store this position in a file named table of available solutions. The process of identification and storing the possible solution will be repeated in order to identify all fixturing possibilities.

At this point, the CAF system will start to determine the best allocation relat $\mathrm{d}$ to the fixturing reactive stresses by engaging the SIMPLIFIED STiESS CALCULATION MODULE - SSCM. This will be done for each possible fixturing position described in the table of available solutions.

The reactive stress points will be tentatively allocated to the available hot points (as described above, the hot points are preferential points for the allocation of the fixtures). If the system does not find any, it will proceed to analyse the part features described in the geometric model received from the CAD system, and, if they still are not found, it will then move on to a section of the part. The reactive stresses will be allocated following the fixturing rule "3:2:1" - (3 supporting points, 2 locating points and 1 clamping point).

The structure of the SSCM will be based on equations to promptly identify a state of equilibrium and rigidity in the assembly. This assumes the workpiece is an inelastic-rigid body. Once the SSCM has estimated the reactive stresses, the CAF system will select, for each possible fixturing position, the fixture elements needed for part fixturing.

The selection will be based on the features connection (parts and fixture elements) and again on the rule "3:2:1" ( 3 base points, 2 locating points and 1 clamping point). The CAF system will identify the workpiece form features where the support reactive stresses were allocated by the SSCM. Based on this information, the CAF will select the support elements which will be related to those form features.

Once the three support elements were selected, the CAF system will repeat the procedure for the two location points and to the clamping point at last. The process of selecting the fixturing alternatives described above will be applied to all available fixturing position described in the table of available solutions. All 
fixtures needed to establish each fixturing solution will be included in the table of available solutions.

At this stage, the fixturing solution will be input again to the SSCM for a fast evaluation on rigidity. If the combination between the workpiece position and the available fixtures fails, the CAF system will discard this possible solution and remove the available fixturing position from the table of available solutions.

On the toher hand, once it is approved, the fixturing set can be submitted to a new checking by being input to the ADVANCED TENSION CALCULATION MODULE (ATCM), where the geometric and dimensional workpiece integrity will too be checked. If this solution proves to be acceptable, the CAF system will store it in the table of approved solutions. It will then move on to analyse the next possible position of part fixturing previously detected.

If the pair possible position / modular fixtures set fails the workpiece integrity check (at the ATCM), the CAF system will suggest the CAPP system to reevaluate the process parameters (cutting conditions) previously specified.

If the CAPP system is unable to give new process parameters, the set of fixturing solutions (the workpiece position and the fixturing solution on analysis) will then be discarded. At this point the CAF system will remove the reproved solution form the table of available solutions and start to evaluate the next stored alternative.

\section{CONCLUSION.}

This work described the structure of a CAF system. Further works will describe the performance testing results concerning the CAF system operation. The development of this system took advantage on the CAD features technology by describing both the workpiece and the fixtures in terms of features. This enables the analysis on fixturing to be based on the conventional stress evaluation as well as to be performed considering all specific geometric and technical information required for manufacture reasoning.

The main advantage arising from the use of such a system is the reduction in fixturing design costs along with allowing the process engineer to work upon the fixturing evaluation effectively integrated to the design and process planning development environments (the CAD and the CAPP systems). This is achieved by basing all systems on the same feature-based part description and then by sharing the same part description models. The approach here described was mainly devised for the milling process evaluation. However, it might prove useful on fixturing design for other similar machining processes, for welding and assembly operations evaluation and even for the measurement operations analysis to be performed on co-ordinate measurement machines (CMM). 


\section{REFERENCES.}

Cabadaj, J. (1990) Theory of computer aided fixture design. Computers in Industry. v.15, p. 141-147.

Caillaud, E. and Noyes, D. (1996) Towards a knowledge-based fixture designer's assistant. Balanced Automation Systems II, p. 373.

Cunha, G. D. and Teixeira, J. J. P. (1993) A Featured-Based Model For Design and Manufacturing Knowledge Representation. In Proceedings of 12th Brazilian Congress of Mechanical Engineering, Rio de Janeiro.

Cunha, G. D. O Conceito de Projecto Orientado à Fabricação Aplicado ao Projecto Assistido por Computador. Doctoral Thesis in Mechanical Engineering. Universidade Nova de Lisboa, 1995, 354p.

Ferreira, P. \& Liu, (1988) C. Generation of workpiece orientation for machining using a ruled-based system. Robotics \& Computer Integrated Manufacturing, v. 4, n. 3/4, p. 545-1.

Liou, F. \& Suen, D. (1991) The development of a feature-based fixture process planning system for flexible assembly. Journal of Manufacturing Systems. v.11, n. 2.

Pereira, G. M. (1996) Análise dos Requisitos para a Estruturação de um Sistema de Fixações Assistido por Computador - CAF. Mastership Thesis in Production Engineering. Universidade Federal do Rio Grande do Sul, Porto Alegre,. 162p.

Pham, D., Nategh, M., Lazaro, A. (1989) A knowledge-based jig and fixture designer's assistant. The International Journal of Advanced Manufacturing Technology. v. 4, p. 26-45.

Shah, J. (1991) Assessment of feature technology. Computer-Aided Design, Guildford, v. 23, n. 5, jun..

\section{ACKNOWLEDGEMENTS.}

This work was partially supported by FAPERGS - The Scientific Research Foundation of the State of Rio Grande do Sul - Brazil - Project No. 96/1502.8.

\section{BIOGRAPHIES.}

Giancarlo Medeiros Pereira received his MS in Industrial Engineering from Universidade Federal do Rio Grande do Sul - UFRGS in 1996. His area of specialisation is Automation Industry, focused in Concurrent Engineering and integration of design systems.

Gilberto Dias da Cunha received hïs $\mathrm{PhD}$ degree in Mechanical Engineering from Universidade Nova de Lisboa in 1996. His research activities concern product design, factory automation and quality assurance - with specific interest in featurebased CAD systems and the application of the Concurrent Engineering and the Design the for Manufacture and Assembly in industry. 